\title{
Определение триацилглицеринов масла семян валерианы лекарственной с использованием обращенно-фразовой ВЭЖХ с двумя способами детектирования
}

\author{
Ань Нгуен Ван, Дейнека В.И., Дейнека Л.А. \\ ФГАОУ ВПО «Белгородский государственный нацииональный исследовательский университет», \\ Белгород
}

Поступила в редакцию 4.05.2017 г.

В работе методом обращенно-фазовой ВЭЖХ с рефрактометрическим и спектрофотометрическим детектированием исследовано масло семян валерианы лекарственной. Отнесение пиков выполнено по инкрементному подходу и показано, что основная кислота масла - $\alpha$-элеостеариновая, - в масле содержится около 4 \% триацилглицеринов (ТАГ), не содержащих радикалы $\alpha$-линоленовой кислоты. Определен видовой состав ТАГ масла (указаны данные по рефрактометрическому и по спектрофотометрическому методам детектирования): основные ТАГ - $\alpha$-элеостеарат-дилинолеат (55.0 / 58.1 моль \%), ди- $\alpha$-элеостеарат-линолеат (16.6 / 14.7 моль \%), $\alpha$-элеостеарат-линолеат-олеат (11.1 / 11.3 моль \%), $\alpha$-элеостеарат-линолеат-пальмитат (7.1 / 7.4 моль \%) и др. Расхождение между данными может быть связано с присутствием в масле изомерных триеновых кислот. Результаты расчета жирнокислотного состава по обоим методам близки между собой: $\alpha$-элеостеариновая кислота 39.2 (39.3) $\%$, линолевая - 51.1 (50.6) \%, олеиновая 5.9 (6.0) \%, пальмитиновая - 2.4 (3.3) \% и стеариновая 1.4 $(0.9) \%$.

Ключевые слова: ВЭЖХ, рефрактометрическое детектирование, спектрофотометрическое детектирование, масло семян валерианы лекарственной, видовой состав триацилглицеринов, $\alpha$ элеостеариновая кислота, высшие жирные кислоты.

\section{Determination of triacylglycerols of seed oil of Valeriana officinalis using a reverse-phase HPLC with two detec- tion methods}

\author{
Anh Van Nguyen, Deineka V.I., Deineka L.A. \\ Belgorod National Research University, Belgorod
}

In the paper the method of reversed-phase HPLC with refractometric and spectrophotometric detection was used for determination of Valeriana officinalis seed oil. The assignment of peaks was made using the flax seed oil in the case of refractometric detection and Momordica charantia seed oil in the case of spectrophotometric detection based on incremental approach and the main oil acid was found to be $\alpha$-eleostearic, while the oil contains only about $4 \%$ of triacylglycerols (TAG), without radicals of $\alpha$-eleostearic acid. The peculiarities of triacylglycerol (TAG) retention parameters calculation in the case of refractometric detections were discussed in terms of column overloading. Mole fraction of seed oil TAGs were calculated upon peak areas (corrected areas in the case of refractometric detection): main one TAG $-\alpha$-eleostearate-dilinoleate (55.0/58.1 mole \%), di- $\alpha$-eleostearic-linoleate $(16.6 / 14.7$ mole $\%)$, $\alpha$-eleostearate-linoleate-oleate $(11.1 /$ 11.3 mole \%), $\alpha$-eleostearate-linoleate-palmitate $(7.1 / 7.4$ mole $\%)$ (the data are given for refractometric and spectrophotometric methods of detection, respectively). Discrepancy between the data may be due to the presence in the oil isomeric triene acids. Fatty acid composition, calculated by both methods are close to each 
other: triene acid $39.2(39.3) \%$, linoleic - $51.1(50.6) \%$, oleic $5.9(6.0) \%$, palmitic $-2.4(3.3) \%$ and stearic $1.4(0.9) \%$.

Keywords: seed oils, triacylglycerols, reversed-phase HPLC, refractive index detection, spectrophotometric detection, Valeriana officinalis, fatty acids, $\alpha$-eleostearic acid, fatty acids.

\section{Введение}

Метод обращенно-фазовой ВЭЖХ в элюентах, составленных из ацетона и ацетонитрила, удобен для определения триацилглицеринов (ТАГ) масел семян растений с рефрактометрическим детектированием [1-3]. Собственная абсорбция ацетона в УФ-диапазоне исключает применение УФ-детектирования; но этот метод может быть использован, во-первых, при замене ацетона на диэтиловый эфир [4], и, вовторых, при использовании высоко токсичного пропионитрила [3, 5]. Очевидно, что вследствие высокой летучести диэтилового эфира возникают технические проблемы, препятствующие широкому использованию элюентов на его основе. Существенный недостаток других альтернативных высокоэффективных вариантов детектирования по светорассеиванию [6] и по анализу масс-спектров [7] связан с дороговизной оборудования.

При любом составе элюентов использование УФ-детектирования для количественного анализа ТАГ остается проблематичным (а точнее, проблема обычно просто игнорируется [8]). Это связано с тем, что остаточная абсорбция за счет электронных переходов в изолированных $\mathrm{C}=\mathrm{C}$-связях в УФ-области (максимум переходов находится в области вакуумного УФ) растет при увеличении числа двойных связей [9]. Наконец, абсорбция неодинакова для различных конфигураций в несопряженных системах [10]. Простое и доступное решение вопроса количественного определения ТАГ в сложных смесях при рефрактометрическом детектировании было предложено ранее [11]. Но основной недостаток рефрактометрического детектирования связан не столько с невозможностью использования градиентного элюирования, сколько с относительно низкой чувствительностью. По этой причине требуется использование более высоких концентраций масла, что может привести к искажению форм пиков, осложняя применение инкрементного подхода для предсказания составов ТАГ в сложных смесях [12].

Цель настоящей работы - определение качественного и количественного состава ТАГ масла семян валерианы лекарственной (Valeriana officinalis L.) с использованием обращенно-фазовой ВЭЖХ. Особенность работы определена тем, что ТАГ масла образованы высшими жирными кислотами, среди которых присутствует октадекатриеновая кислота с сопряженными двойными связями [13], что позволяет для контроля масел использовать не только рефрактометрическое, но и спектрофотометрическое детектирование.

\section{Эксперимент}

Семена валерианы лекарственной были приобретены в магазине для садоводов-огородников (Седек), а момордики харантия были выделены из плодов растений, выращенных в Белгороде. Льяное масло было приобретено в гипермаркете.

Масла из измельченных семян экстрагировали порциями $н$-гексана по $5 \mathrm{~cm}^{3}$ при растирании в фарфоровой ступке $(\mathrm{P}=0.1)$, объединенные порции отфильтровывали через бумажный фильтр. Для предотвращения разрушения сопряженных полиеновых соединений экстракцию проводили без нагревания. Экстракт очищали методом твердофазной экстракции на насадочных картриджах ДИАПАК С (БиоХимМак СТ, Москва). Перед сорбцией через насадку пропускали $6 \mathrm{~cm}^{3}$ н-гексана. Затем проводили сорбцию масла из $20 \mathrm{~cm}^{3}$ его раствора в $H$-гексане с концентрацией около 
10 мг/см³. Масло десорбировали с силикагеля дихлорметаном. Растворитель удаляли на вакуумном ротационном испарителе и остаток растворяли в подвижной фазе для ВЭЖХ определения.

Для определения масел использовали обращенно-фазовую ВЭЖХ на хроматографе Agilent 1200 Infinity: a) с рефрактометрическим детектором R 401 (Waters Millipore), записывая хроматограммы при использовании подвижной фазы 30 об. \% ацетонитрила в ацетоне, $1 \mathrm{~cm}^{3} /$ мин; б) с диодно-матричным детектором, записывая хроматограммы при 274 нм в подвижной фазе 45 об.\% пропанола-2 в ацетонитриле, $1 \mathrm{~cm}^{3} /$ мин. В обоих случаях использовали колонку 250×4.6 мм Kromasil 100-5C18, при температуре термостата $30{ }^{\circ} \mathrm{C}$. Для записи хроматограмм сопряженных триеновых соединений ацетон, как добавка к подвижной фазе, не приемлем из-за собственного поглощения на аналитической длине волны, но он может быть легко замен на легко доступный пропанол- 2 требуемой чистоты, не имеющий такого недостатка.

Триацилглицерины обозначали традиционно принятым способом - указывали буквенные обозначения радикалов высших жирных кислот X - октадекатриеновой, Л - линолевой, $\mathrm{O}$ - олеиновой, П - пальмитиновой и С стераниновой без уточнения их положения в молекуле ТАГ. Так, например, ЛО 2 - обозначает линоленоат-диолеат глицерина; ХЛО - октадекатриеноат-линолеат-стеарат глицерина.

\section{Обсуждение результатов}

Так как масло семян валерианы образовано ТАГ с участием сопряженных октадекатриеновых кислот, то для первичного контроля экстракта семян валерианы в $\mu$-гексане был записан его электронный спектр, рис. 1.

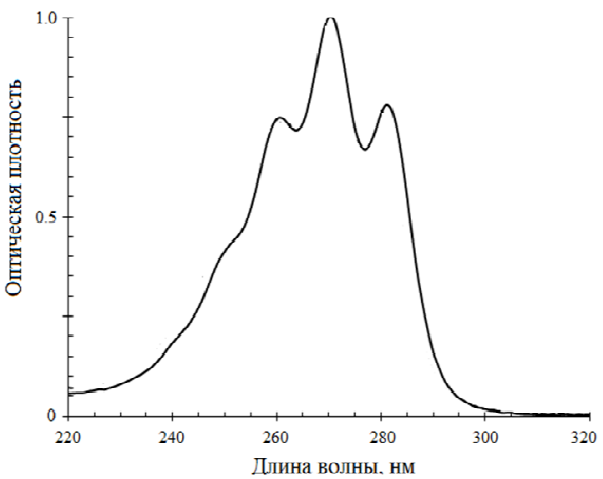

Рис. 1. Спектр экстракта семян валерианы лекарственной

На рис. 1 представлен характерный для сопряженных триеновых соединений спектр с электронно-колебательной структурой с максимумами абсорбции в диапазоне от 255 до 285 нм. Следовательно, по крайней мере, часть ТАГ может быть зарегистрирована на хроматограмме с использованием спектрофотометрического детектора. Однако перед использованием спектрофотометрического детектирования необходимо убедиться в отсутствии или оценить долю ТАГ, не содержащих радикалов сопряженных кислот, используя рефрактометрическое детектирование.

При относительно высокой концентрации масел в анализируемых образцах с применением рефрактометрического детектирования возможно искажение формы пика и времен удерживания ТАГ вследствие выхода изотермы абсорбции за пределы области Генри. Влияние концентрации масла в анализируемой пробе на получаемые хроматографические параметры анализировали, сопоставляя хроматограммы серии проб растворов льняного масла с последовательно уменьшающейся концентрацией, рис. 2. 


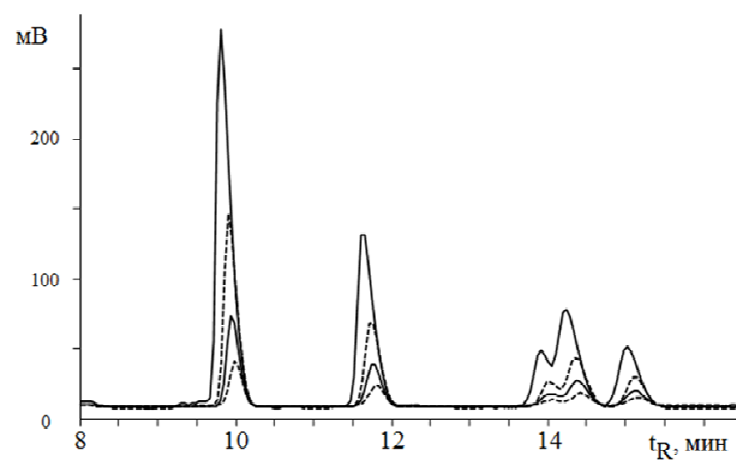

Рис. 2. Фрагменты хроматограмм проб льняного масла с различными концентрациями

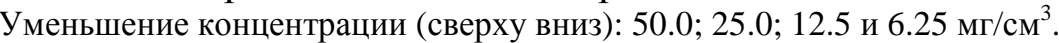

Подвижная фаза 30 об.\% $\mathrm{CH}_{3} \mathrm{CN}$ в ацетоне, 1 мл/мин; детектор рефрактометрический.

По хроматограммам, представленным на рис. 2, видно, что формы пиков ТАГ для начальной пробы $\left(50 \mathrm{Mг} / \mathrm{cm}^{3}\right)$ заметно искажены, но при разбавлении они постепенно «улучшались», и для концентрации 6.26 мг/Г коэффициент асимметрии снизился от 2.55 до 1.15 для трилинолеата. Однако важные для расчета состава ТАГ разности логарифмов факторов удерживания, определенные по временам, соответствующим максимумам пиков, при однотипных заменах радикалов в ТАГ [12] изменялись в существенно меньшей степени (табл. 1). Наконец, экспериментально было установлено, что в качестве наиболее удобной оценки времени удерживания индивидуальных ТАГ при не очень большой перегрузке колонки (в данном случае при концентрации масла менее $25 \mathrm{mг} / \mathrm{cm}^{3}$ ) можно использовать время, соответствующее середине основания пика при рефрактометрическом детектировании. В таком случае применение инкрементного подхода без погрешностей, превышающих 0.002 лога-

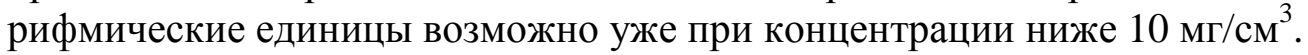

Таблица 1. Параметры удерживания ТАГ льняного масла и масла семян валерианы в элюенте 30 об.\% ацетонитрила в ацетоне при рефрактометрическом детектировании

\begin{tabular}{|c|c|c|c|c|c|c|c|c|c|c|c|}
\hline \multirow{2}{*}{ № } & \multirow{2}{*}{ Вид ТАГ } & \multirow{2}{*}{$\mathrm{t}_{\mathrm{R}}, \mathrm{мин}$} & \multicolumn{4}{|c|}{ Инкременты* } & \multirow{2}{*}{$\mathrm{t}_{\mathrm{R}}, \mathrm{мин}$} & \multicolumn{4}{|c|}{ Инкременты* } \\
\hline & & & $\mathrm{X} \rightarrow \Omega$ & $Л \rightarrow \mathrm{O}$ & $\mathrm{O} \rightarrow \Pi$ & $\Pi \rightarrow \mathrm{C}$ & & $\mathrm{X} \rightarrow \pi$ & $\pi \rightarrow \mathrm{O}$ & $\mathrm{O} \rightarrow \Pi$ & $\Pi \rightarrow \mathrm{C}$ \\
\hline & & & \multicolumn{4}{|c|}{ льняное масло } & & \multicolumn{4}{|c|}{ масло семян валерианы } \\
\hline 1 & 2 & 3 & 4 & 5 & 6 & 7 & 8 & 9 & 10 & 11 & 12 \\
\hline 1 & $\mathrm{X}_{3}$ & 8.35 & & & & & 8.95 & & & & \\
\hline 2 & $\mathrm{X}_{2} \Omega$ & 9.90 & 0.102 & & & & 10.38 & 0.087 & & & \\
\hline 3 & $\mathrm{X} Л_{2}$ & 11.86 & 0.102 & & & & 12.16 & 0.088 & & & \\
\hline 4 & $\mathrm{X}_{2} \mathrm{O}$ & 12.16 & & 0.116 & & & 12.76 & & 0.115 & & \\
\hline 5 & $\mathrm{X}_{2} \Pi$ & 12.79 & & & 0.027 & & 13.42 & & & 0.027 & \\
\hline 6 & $\pi_{3}$ & 14.35 & & & & & 14.41 & & & & \\
\hline 7 & ХЛО & 14.73 & 0.102 & 0.116 & & & 15.11 & 0.09 & 0.116 & & \\
\hline 8 & ХЛП & 15.55 & & & 0.028 & & 15.92 & & & 0.027 & \\
\hline 9 & $\mathrm{X}_{2} \mathrm{C}$ & 15.70 & & & & 0.108 & 16.52 & & & & 0.109 \\
\hline 10 & $\pi_{2} \mathrm{O}$ & 17.93 & & 0.115 & & & 18.05 & & 0.116 & & \\
\hline 11 & $\mathrm{XO}_{2}$ & 18.49 & & 0.116 & & & 18.98 & & 0.116 & & \\
\hline 12 & ХЛС & 19.25 & & & & 0.108 & 19.69 & & & & 0.108 \\
\hline & Средн & & 0.102 & 0.116 & 0.028 & 0.108 & & 0.088 & 0.116 & 0.027 & 0.1 \\
\hline
\end{tabular}

Хроматограмма масла семян валерианы на фоне хроматограммы льняного масла при рефрактометрическом детектировании представлена на рис.3, а результаты обработки параметров удерживания пиков представлены в табл. 2. 


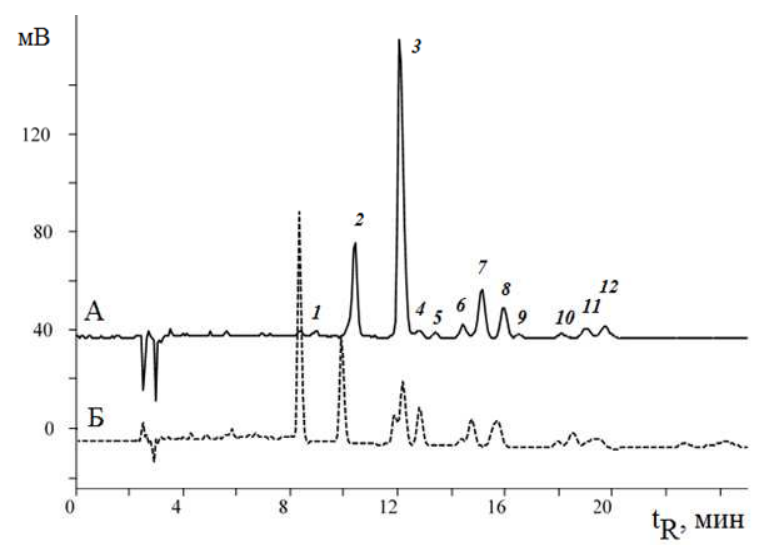

Рис. 3. Хроматограммы масла семян валерианы и льняного масла Подвижная фаза 30 об.\% $\mathrm{CH}_{3} \mathrm{CN}$ в ацетоне, $1 \mathrm{~cm}^{3} /$ мин; детектор рефрактометрический. Хроматограммы: А - масла семян валерианы, Б - льняного масла.

Отнесение пиков на хроматограмме - см. Табл. 1.

Таблица 2. Параметры удерживания ТАГ масла семян валерианы и момордики харантия в элюенте 45 об.\% 2-пропанола в ацетонитриле при спектрофотометрическом детектировании (270 нм)

\begin{tabular}{|c|c|c|c|c|c|c|c|c|c|}
\hline \multirow{2}{*}{ № } & \multirow{2}{*}{ Вид ТАГ } & \multicolumn{2}{|c|}{$\mathrm{t}_{\mathrm{R}}$, мин ТАГ масел семян } & \multicolumn{4}{|c|}{ Инкременты } & \multicolumn{2}{|c|}{ Доля ТАГ*, моль \% } \\
\hline & & V. officinalis & M. charantia & $\mathrm{X} \rightarrow \pi$ & $\Omega \rightarrow O$ & $\mathrm{O} \rightarrow \Pi$ & $\Pi \rightarrow \mathrm{C}$ & КП* & CФ* \\
\hline 1 & $\mathrm{X}_{3}$ & 10.81 & 10.81 & & & & & 0.9 & 0.4 \\
\hline 2 & $\mathrm{X}_{2} \Omega$ & 12.71 & 12.69 & 0.089 & & & & 16.6 & 14.7 \\
\hline 3 & $\mathrm{X} \Omega_{2}$ & 15.04 & 15.04 & 0.089 & & & & 55.0 & 58.1 \\
\hline 4 & $\mathrm{X}_{2} \mathrm{O}$ & 16.09 & 16.05 & & 0.124 & & & 1.5 & 1.2 \\
\hline 5 & $\mathrm{X}_{2} \Pi$ & 16.98 & 16.99 & & & 0.028 & & 0.7 & 0.6 \\
\hline 6 & ХЛО & 19.19 & 19.16 & 0.089 & 0.124 & & & 11.1 & 11.3 \\
\hline 7 & ХЛП & 20.32 & - & & & 0.028 & & 7.1 & 7.4 \\
\hline 8 & $\mathrm{X}_{2} \mathrm{C}$ & 21.44 & 21.43 & & & & 0.117 & 0.7 & 0.4 \\
\hline 9 & $\mathrm{XO}_{2}$ & 24.72 & 24.68 & & 0.124 & & & 2.6 & 1.8 \\
\hline 10 & ХЛС & 25.80 & 25.76 & & & & 0.116 & 3.8 & 4.1 \\
\hline
\end{tabular}

* - в масле валерианы.

На хроматограмме масла семян валерианы обнаруживаются двенадцать ТАГ, состав которых легко рассчитывается по инкрементному подходу (табл. 2). При сравнении с хроматограммой льняного масла устанавливается, что одинаковым изменениям структуры ТАГ соответствуют одинаковые инкременты - для замены линолевой кислоты на олеиновую (0.116 логарифмических единиц), олеиновой на пальмитиновую (0.028) и пальмитиновой на стеариновую (0.108). При этом удерживание всех ТАГ, содержащих радикалы триеновой кислоты масла семян валерьяны заметно больше, чем у соответствующих ТАГ льняного масла, что указывает на их различное строение.

На пики ТАГ, не содержащих сопряженную триеновую кислоту, приходится менее $4 \%$ суммарной площади пиков (при расчетах учитывали поправочные коэффициенты, учитывающие изменение отклика рефрактометрического детектора при изменении состава ТАГ, предложенные в [11]). Рассчитанный по найденному видовому составу масла жирнокислотный состав: триеновая кислота 39.2 (40.5) \%, линолевая - 51.1 (49.5) \%, олеиновая 5.9 (5.9) \%, пальмитиновая - 2.4 (2.6) \% и стеариновая 1.4 (1.5) \%. В скобках - расчет масла без учета площадей пиков, которые не будут видны при использовании спектрофотометрического детектирования.

Следующая задача - определение конфигурации триеновой кислоты в масле семян валерианы (или подтверждение того, что триеновая кислота является $\alpha$ - 
элеостеариновой). Анализ электронных спектров не позволяет решить данную задачу, поскольку при транс-конфигурации центральной (из трех сопряженных) связи возможны три варианта конфигурации боковых $\mathrm{C}=\mathrm{C}$-связей, рис.3. И, в соответствие с эмпирическими правилами [9] при замене изис-связи на транс-конфигурацию должен наблюдаться гипсохромный сдвиг максимумов абсорбции, т.е. в случае соединений с сопряженными триеновыми связями возможно появление трех типов электронных спектров. Но параметры электронных спектров, во-первых, не зависят от того, к какой части кислоты (к карбоксильной группе или к концевой метильной группе) ориентирована несимметричная система из трех сопряженных связей. Вовторых, положение этих связей по длине кислотного радикала может быть различным. По этой причине трем типам электронных спектров может соответствовать большое число жирнокислотных радикалов различного строения. Но в природных объектах обнаружено только 6 изомерных сопряженных октадекатриеновых кислот: 1) жакарандовая, 2) пуниковая, 3) календовая, 4) катальповая, 5) $\alpha$-элеостеариновая и 6) $\beta$-элеостеариновая (номера кислот, положение и конфигурация двойных связей соответствуют номерам, приведенным на рис.4). В таком случае наиболее надежным методом является контроль времен удерживания при сравнении с известными источниками масел с известным строением радикалов октадекатриеновых кислот. Так, для подтверждения присутствия радикалов $\alpha$-линоленовой кислоты в исследуемом масле можно воспользоваться маслом семян момордики харантия $[14,15]$, как образцом сравнения, рис.5. При совпадении времен удерживания ТАГ исследуемого масла и ТАГ масла, используемого в качестве образца сравнения, гипотеза об идентичности состава ТАГ может быть подтверждена совпадением электронных спектров.

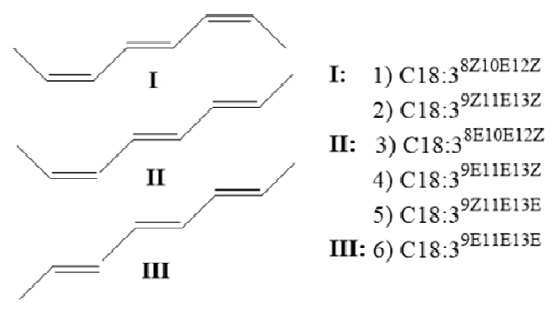

Рис. 4. Строение сопряженных двойных связей в молекулах природных октадекатриеновых высших жирных кислот

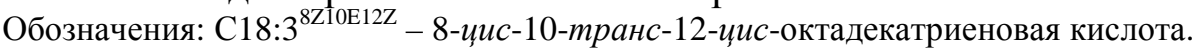

Как следует из рис. 5 масло семян валерианы образовано ТАГ, удерживание которых совпадает с соответствующими ТАГ масла момордики харантия (при полном совпадении электронных спектров), что позволяет, во-первых, подтвердить участие $\alpha$-элеостеариновой кислоты в образовании ТАГ, во-вторых, провести полное отнесение пиков на хроматограмме, табл.2.

При спектрофотометрическом детектировании вследствие более высокой чувствительности детектора можно использовать значительно меньшие концентрации образца в пробах (менее $1 \mathrm{~cm}^{3} / \mathrm{cm}^{3}$ ), что позволяет получать достаточно симметричные пики и использовать время удерживания в максимуме пика в качестве параметра удерживания. Для найденных параметров удерживания также соблюдаются инкрементные разности, табл.2. Но доля ТАГ в масле по данным площадей пиков несколько отличается от таковой для рефрактометрического детектирования. Это может быть следствием того, что при УФ-детектировании проблемы количественного анализа связаны с существованием изомерных $\alpha$-элеостеариновой кислоте радикалов в составе ТАГ, что проявляется в усложнении структуры, например, пика №2

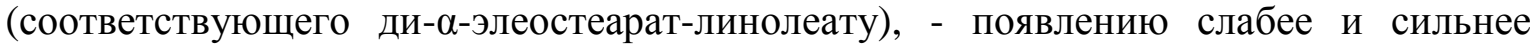


удерживающихся компонентов с неполным отделением от основного пика. Изомерный характер пиков подтверждается неидентичностью их электронных спектров. Рассчитанный по найденному видовому составу масла жирнокислотный состав: $\alpha$-элеостеариновая кислота $39.3 \%$, линолевая - $50.6 \%$, олеиновая $6.0 \%$, пальмитиновая $-3.3 \%$ и стеариновая $0.9 \%$, что хорошо (расхождение менее $1 \%$ ) коррелирует с данными, полученными по расчету при рефрактометрическом детектировании.

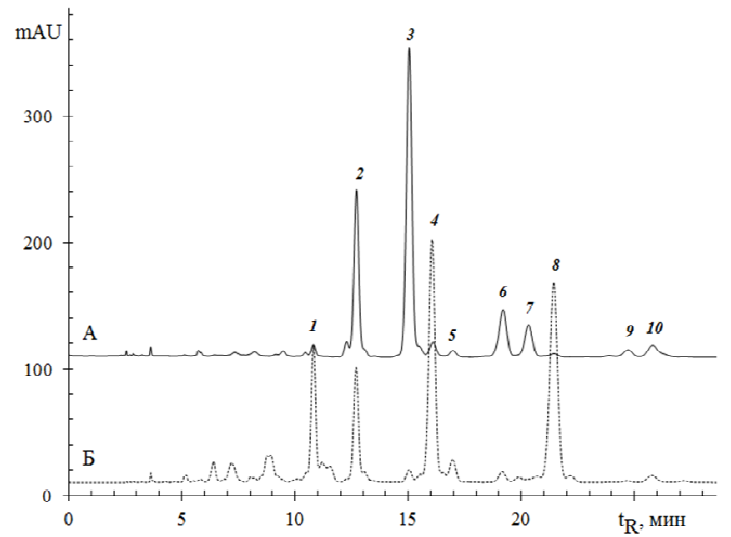

Рис.5. Хроматограммы масла семян валерианы и семян момордики харантия

Подвижная фаза 45 об.\% 2-пропанола в ацетонитриле, 1 мл/мин; детектор диодноматричный, запись при $\lambda=274$ нм. Хроматограммы: А - масла семян валерианы, Б - масла семян момордики харантия. Отнесение пиков на хроматограмме - см. Табл. 2.

\section{Заключение}

Таким образом, методом обращенно-фазовой ВЭЖХ с рефрактометрическим и спектрофотометрическим детектированием исследовано масло семян валерианы лекарственной. Показано, что возможно отнесение пиков по инкрементному подходу в обоих вариантах детектирования, несмотря на перегрузку колонки при спектрофотометрическом детектировании. Это позволило, используя оба метода детектирования, предсказать видовой состав ТАГ, так и рассчитать по нему жирнокислотный состав, получая согласованные результаты.

\section{Список литературы}

1. Wolf J.P., Mordret F.X., Dieffenbacher A. // Pure Appl. Chem. 1991. Vol. 63. pp. 11731182.

2. 2 Дейнека В.И., Дейнека Л.А., Туртыгин А.В. // Сорбиионные и хроматографические проиессы. 2008. Т. 8. № 3. С. 465-477.

3. Podlaha O., Töregård B. // J. Sep. Sci. 1982. Vol. 5. pp. 553-558.

4. Дейнека В.И., Дейнека Л.А. // Журнал аналитической химии. 2004. Т. 59. № 9. С. 895-898.

5. Frede E. // Chromatographia. 1986. Vol. 21. No 1. pp. 29-36.

6. Letter W.S. // J. Liq. Chromat. 1993. Vol. 16. No 1. pp. 225-239.

7. Holčapek M., Lísa M., Jandera P., Kabtov N. // J. Sep. Sci. 2005. Vol. 28, pp. 1315-1333.

8. Herslöf B.G. // J. Sep. Sci. 1981. Vol. 4. 9. Бренд Дж.К.Д., Скотт А.И. Применение ультрафиолетовой спектроскопии / В кн. «Установление структуры органических соединений физическими и химическими методами». Ред. А. Вайсбергер. Пер. с англ. М.: Химия. 1967. С.91-94.

10.Дейнека В.И., Дейнека Л.А. // Химия растительного сырья 2006. № 3. С. 21-26.

11.Дейнека В.И., Дейнека Л.А., Габрук Н.Г., Фофанов Г.М. и др. // Журнал аналитической химии. 2003. Т .58. № 11. С. 12941299.

12.Дейнека В.И., Староверов В.М., Фофанов Г.М., Балятинская Л.Н. // Хим.-фарм. ж. 2002. T. 36. № 7. C. 44-47.

13.Chisholm M.J.; Hopkins C.Y. // J. Amer. Oil. Chem. Soc. 1966. Vol. 43. pp. 390-392. pp. 471-473. 
14.Chang M.-K., Conkerton E.J., Chapital D.C., Wan P.J. et al. // J. Amer. Oil Chem. Soc. 1996. Vol. 73. pp. 263-265.

\section{References}

1. Wolf J.P., Mordret F.X., Dieffenbacher A., Pure Appl. Chem., 1991, Vol. 63, pp. 11731182.

http://dx.doi.org/10.1351/pac199163081173.

2 Deineka V.I., Deineka L.A., Turtygyin A.V., Sorbtsionnye i khromatograficheskie protsessy, 20108 Vol. 8, No 3, pp. 465-477.

3. Podlaha O., Töregård B., J. Sep. Sci., 1982, Vol. 5, No 10, pp. 553-558. DOI: 10.1002/jhrc.1240051007. Available at: http://onlinelibrary.wiley.com/doi/10.1002/jhrc. 1240051007/abstract

4. Deineka V.I., Deineka L.A., J. Anal. Chem., 2004, Vol. 59, No 9, pp. 895-898. DOI:10.1023/B:JANC.0000040709.11986.f2.

Available at: https://link.springer.com/ article/10.1023/B:JANC.0000040709.

11986.f2

5. Frede E., Chromatographia, 1986, Vol. 21, No 1, pp. 29-36. DOI: 10.1007/BF02310591. Available at: https://link.springer.com article/10.1007/BF02310591

6. Letter W.S., J. Liq. Chromat., 1993, Vol. 16, No 1, pp. 225-239. http://dx.doi.org/ 10.1080/10826079308020908.

7. Holčapek M., Lísa M., Jandera P., Kabtov N., J. Sep. Sci., 2005, Vol. 28, pp. 1315-1333. DOI: $10.1002 /$ jssc. 200500088 . Available at http://onlinelibrary.wiley.com/doi/10.1002/jssc. 200500088/abstract.

8. Herslöf B.G., J. Sep. Sci., 1981, Vol. 4, No 9, pp. 471-473. DOI: 10.1002/jhrc.1240040911. Available at: http://onlinelibrary.wiley.com/doi/ 10.1002/jhrc. 1240040911/abstract.

Нгуен Ван Ань - аспирант кафедры общей химии, Белгородский государственный национальный исследовательский университет, Белгород

Дейнека Виктор Иванович - профессор кафедры общей химии, д.х.н., Белгородский государственный национальный исследовательский университет, Белгород

Дейнека Людмила Александровна - доцент кафедры общей химии, к.х.н., Белгородский государственный национальный исследовательский университет, Белгород
15.Fu W.-C., Gu X.-H., Tao G.-J., Tang J., Jiang Z.-L. // J. Amer. Oil Chem. Soc. 2009. Vol. 86. pp. 33-39.

9. Brend J.K.D., Skott A.I. Primenenie ultrafioletovoj spektroskopii v ustanovlenie struktury organicheskih soedinenij fizicheskimi i himicheskimi metodami. Prod. A. Vajsberger (transl. from English),. M., Himiya. 1967, pp. 91-94.

10. Deineka V.I., Deineka L.A., Himiya Rastitelnogo Syrya, 2006, No 3, pp. 21-26.

11. Deineka V.I., Deineka L.A., Gabruk N.G., Fofanov G.M. et al., J. Anal. Chem. 2003, Vol. 58, No. 12, pp. 1160-1165. doi:10.1023/B:JANC.0000008956.07835.51.

Available at: https://link.springer.com/article /10.1023/B\%3AJANC.0000008956.07835.51.

12. Deineka V.I., Staroverov V.M., Fofanov G.M., Balyatinska L.N., Pharm. Chem. J., 2002, Vol. 36, No 7, pp. 392-395. DOI: 10.1023/A:1021004516406 Available at: https://link.springer.com/article/10.1023/A\%3A 1021004516406.

13. Chisholm, M. J.; Hopkins, C. Y., J. Amer. Oil. Chem. Soc., 1966, Vol. 43, pp. 390-392. DOI: $\quad 10.1007 / \mathrm{BF} 02646796$ Available at https://link.springer.com/article/10.1007/BF026 46796.

14. Chang M.-K., Conkerton E.J., Chapital D.C., Wan P.J., Vadhwa O.P., Spiers J.M., J. Amer. Oil Chem. Soc., 1996, Vol. 73, pp. 263265. DOI: $10.1007 / \mathrm{BF} 02523907$. Available at https://link.springer.com/article/10.1007/BF0 2523907.

15. Fu W.-C., Gu X.-H., Tao G.-J., Tang J., Jiang Z.-L., J. Amer. Oil Chem. Soc., 2009, Vol. 86, pp. 33-39. DOI: 10.1007/s11746-0081313-z. Available at https://link.springer.com /article/10.1007/s11746-008-1313-z.

Nguyen Van Anh - Postgraduate of Common Chemistry Chair of Institute of Engineering Technologies and Natural Sciences of Belgorod State National Research University, e-mail: vananhkhoahoasp2@gmail.com

Deineka Victor I. - professor of Common Chemistry Chair of Institute of Engineering Technologies and Natural Sciences of Belgorod State National Research University. Dr. Sci. (Chemistry), e-mail: deineka@bsu.edu.ru

Deineka Ludmila A. - professor assistant of Common Chemistry Chair of Institute of Engineering Technologies and Natural Sciences of Belgorod State National Research University. Ph.D. (Chemistry), e-mail: deyneka@bsu.edu.ru 